\title{
Business Process Management in the Large
}

\section{DOI 10.1007/s12599-011-0181-5}

\section{The Authors}

Dipl.-Wirt.-Inf. (DH)

Constantin Houy M.A. ( $ه)$

PD Dr. Peter Fettke

Prof. Dr. Peter Loos

Institute for Information Systems

(IWi) at the German Research Center

for Artificial Intelligence (DFKI) $\mathrm{GmbH}$

and Saarland University

Campus D3 2

66123 Saarbrücken

Germany

constantin.houy@iwi.dfki.de

peter.fettke@iwi.dfki.de

peter.loos@iwi.dfki.de

Prof. Wil M.P. van der Aalst, PhD

Department of Mathematics and

Computer Science

Technische Universiteit Eindhoven

(TU/e)

Den Dolech 2

5612 AZ Eindhoven

The Netherlands

w.m.p.v.d.aalst@tue.nl

Prof. John Krogstie, PhD

Department of Computer and

Information Science

Norges Teknisk-Naturvitenskapelige

Universitet (NTNU)

Sem Sælandsvei 7-9

7491 Trondheim

Norway

krogstie@idi.ntnu.no

Received: 2011-04-11

Accepted: 2011-09-08

Accepted after one revision

by Prof. Dr. Sinz.

Published online: 2011-11-08

This article is also available in German in print and via http://www. wirtschaftsinformatik.de: Houy C, Fettke $\mathrm{P}$, Loos $\mathrm{P}$, van der Aalst WMP, Krogstie J (2011) Geschäftsprozessmanagement im Großen. WIRTSCHAFTSINFORMATIK. doi: $10.1007 /$ s11576-011-0292-0.

(c) Gabler Verlag 2011

\section{Increasing Complexity of Business Processes}

In recent years Business Process Management (BPM) has attracted considerable attention, both in academia and practice. A growing research community is designing and investigating BPM approaches and techniques which are meanwhile widely used in private and public organizations. The quantity and quality of literature concerning BPM, the existence of specialized conferences (e.g., the International BPM Conference) as well as dedicated journals (e.g., the Business Process Management Journal) illustrate that BPM has become an established discipline. Despite the growing maturity of the BPM discipline, many approaches have problems dealing with the challenges posed by real-life BPM applications. Corporate reality is often more challenging than assumed by contemporary BPM approaches. This situation is similar to the situation of modeling enterprise data (Scheer and Hars 1992). Common enterprise-wide data models tend to be complex, difficult to maintain, and mostly lack in supporting flexible and decentralized organizational structures. In order to be able to maintain the different subareas of an enterprise-wide data model and to reduce the maintenance complexity, adequate abstraction concepts are needed. The same applies to BPM which also requires adequate abstraction concepts to handle real-life complexity. Large organizations have hundreds of different processes in place. Well-established reference process models, such as Scheer's Reference Model for Industrial Enterprises (Scheer 1994) as well as the SAP reference model, are often disconnected from reality; real-life companies' actual business processes are often poorly documented and relationships between different process types are not clearly denoted (Mendling et al. 2008). While conventional BPM research often seems to concentrate on single processes or scenarios comprising a few isolated processes, the upcoming challenge for BPM is to cope with large sets of interdependent interorganizational processes in our globalized and interconnected world. This sit- uation mainly originates from the possibilities created by technical innovations enabling ubiquitous computing, such as smart mobile devices, sensor technologies, or RFID. However, these possibilities also result in increasing complexity and dynamicity of business processes. Since existing BPM techniques and tools cannot handle this well, current research activities focus on new approaches for Business Process Management in the Large (BPM-in-the-Large).

\section{Business Process Management in the Large}

The above described development is comparable to other fields of IS research which have developed dedicated approaches for complexity handling mostly relating to the concept of "Programming in the Large" (DeRemer and Kron 1975). Such approaches are, e.g., "Software Engineering in the Large" (Chiang 1987), "Megaprogramming" (Wiederhold et al. 1992), "Process Modeling in-the-Large" for Software Development Processes (Bandinelli et al. 1993), "Data Modeling in the Large" (Bertram 1994), "Process Management In-theMany" (Graw and Gruhn 1995), and "Modeling in the Large (MODILA)" for Business Processes (Raduescu et al. 2006). In addition, well known concepts like "Very Large Databases (VLDB)" and "Very Large Business Applications (VLBA)" (Grabski et al. 2007) support very similar ideas of handling increasing complexity in different application areas. Recently, more and more BPM approaches and techniques started to focus on handling complexity and dynamicity throughout the whole BPM life cycle. Collaborative modeling, configurable process models, and process mining are examples of approaches which can be summarized under the term "BPM-inthe-Large" (Houy et al. 2010b). In comparison with "BPM-in-the-Small", these approaches support a better complexity handling in real-life BPM scenarios, both tapping automation potential arising from the vast amount of event data generated by the Internet of Things as well as assisting human actors in designing and coordinating complex real- 
Table 1 Characteristics of BPM-in-the-Small and BPM-in-the-Large, inspired by Vanderhaeghen et al. (2010)

\begin{tabular}{|c|c|c|}
\hline Characteristics & BPM-in-the-Small & BPM-in-the-Large \\
\hline $\begin{array}{l}\text { 1. Temporal and spatial extent of process } \\
\text { definitions }\end{array}$ & $\begin{array}{l}\text { Focus on one or just a few cooperating } \\
\text { organizations }\end{array}$ & $\begin{array}{l}\text { Focus on comprehensive business } \\
\text { networks and ecosystems involving } \\
\text { multiple organizations }\end{array}$ \\
\hline 2. Structuring of processes & Often a priori fixed process structures & $\begin{array}{l}\text { More flexible process structures which } \\
\text { have to be adapted to changing situations }\end{array}$ \\
\hline 3. Number of different process types & $\begin{array}{l}\text { Often a priori fixed number of defined } \\
\text { core and support processes }\end{array}$ & $\begin{array}{l}\text { Increasing number of processes through } \\
\text { configurable process models and large } \\
\text { process portfolios }\end{array}$ \\
\hline 4. Dependency between processes & Often few dependencies & Many dependencies \\
\hline 5. Number of process stakeholders & $\begin{array}{l}\text { Low number of stakeholders in single } \\
\text { processes }\end{array}$ & $\begin{array}{l}\text { High number of stakeholders in } \\
\text { inter-organizational processes }\end{array}$ \\
\hline 6. Dynamics of process change & $\begin{array}{l}\text { Often stable and seldom changed process } \\
\text { structures }\end{array}$ & $\begin{array}{l}\text { Often adapted and flexibly configured } \\
\text { process structures }\end{array}$ \\
\hline $\begin{array}{l}\text { 7. Heterogeneity of applied modeling } \\
\text { notations }\end{array}$ & Low heterogeneity & High heterogeneity \\
\hline $\begin{array}{l}\text { 8. Number of different coordinating } \\
\text { institutions of cooperative processes }\end{array}$ & Low & High \\
\hline 9. Dominant planning direction & Top-down, often central organization & Bottom-up, decentralized organization \\
\hline 10. Architecture for BPM systems & Often monolithic & Loosely coupled BPM services \\
\hline
\end{tabular}

life business processes. Table 1 summarizes important characteristics and distinguishing features of BPM-in-theSmall and BPM-in-the-Large.

Topics related to BPM-in-the-Large are gaining importance. This is illustrated by dedicated workshops such as the "Process in the Large" workshop at the 8th BPM conference in 2010. Against the background of the practical and scientific relevance, many application areas and numerous research endeavors exist related to designing and investigating techniques for BPM-in-the-Large.

\section{Application Areas and Current Techniques Supporting BPM-in-the-Large}

Relevant application areas and currently investigated techniques for BPM-in-theLarge can be systemized based on the BPM life cycle as approaches for each of its phases are investigated. In the following, a selection of relevant ideas and research interests contributing to BPM-inthe-Large are described and positioned in the BPM life cycle (Fig. 1). The following ideas can partly also contribute to BPMin-the-Small or pick up ideas from the context of other current BPM trends; e.g., BPM 2.0 which applies social software concepts for BPM (Kurz 2011). However, they address the aforementioned characteristic requirements concerning large and complex process scenarios in the first place.

In the process strategy development phase of the BPM life cycle, business strategy and strategic partnerships identify inter-organizational core business processes and inform the modeling phase for the development of large scale process models. Such models offer the possibility to improve the steering of large inter-organizational value creation networks. Typically, information quality for strategy development is improved during the process of continuous process improvement. Based on event data gathered with sensors during the process life cycle (Houy et al. 2010c) and process mining approaches (van der Aalst et al. 2007), crucial organizational structures can be identified and strategic decisions can be based on real historic data ("evidence-based BPM"). Furthermore, business process maturity models (BPMMs) support the strategic improvement of process organization and can take cross-organizational process management into account (van Looy 2010). Moreover, smart solutions for automated business process maturity assessment are currently developed which can serve for adapting maturity levels in strategic alliances between different organizations.

Many research initiatives contributing to BPM-in-the-Large concentrate on the process definition and modeling phase as process models provide the basis for the whole BPM life cycle. In inter-organizational scenarios, approaches for collaborative process modeling play an important role as they can support a collective understanding of inter-organizational business processes (Rittgen 2009; Dollmann et al. 2011). Reference modeling is also of importance in BPM-in-the-Large. Reference models aim at describing best practice process structures (Fettke and Loos 2004) and can also be formulated for and significantly affect large process scenarios. Especially in large scenarios different dimensions of process quality have an important impact on process performance and organizational success (Krogstie et al. 2006). In order to be able to assess the different quality dimensions, models have to be evaluated from different perspectives. Thus, capable methods and measurement concepts of pluralistic model quality evaluation are currently investigated, e.g. in the research project "PluralistiQue" conducted at the IWi at the DFKI funded by the German Research Foundation (DFG). Another interesting approach supporting the effective design and implementation of processes is concerned with the identification of structural analogies in process models expressing similarity of model constructs which can be useful for the reduction of complexity by providing "common parts" of business process models (Houy et al. 2010b). 
Fig. 1 Current related work on BPM-in-the-Large systemized by the BPM life cycle, based on Houy et al. (2010a)

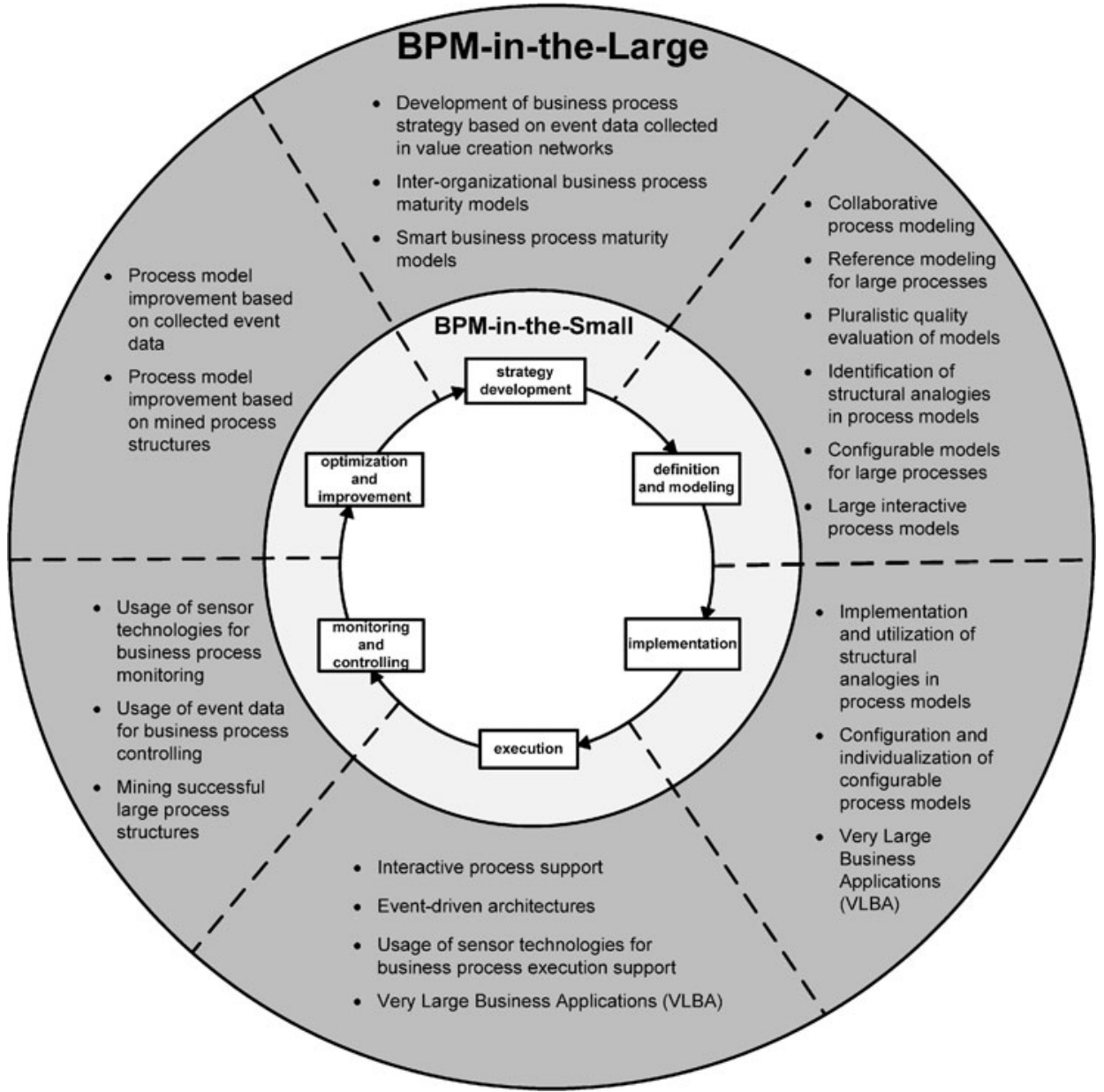

Besides the implementation of identified structural analogies, concepts like configurable models (http://www. processconfiguration.com) (Gottschalk et al. 2008) as well as interactive process models (Jørgensen and Krogstie 2008) are of special importance during the implementation and execution phase. Both concepts support flexible process implementation and execution and thus a more agile BPM. High agility and fast reactions on changing situations are important for process performance. In this context event-driven architectures (EDA) based on sensors collecting event data play an important role as they can facilitate interactive process support. Especially in large process scenarios a plethora of event data is collected and can be used to improve process performance and the agility of reactions on changing business situations (Houy et al. 2010c). Research on Very Large Business Applications (VLBA) is concerned with an effective and efficient implementation and execution of a large number of interdependent processes in internal and inter-organizational contexts (Grabski et al. 2007).

Event data collected during process execution in large EDA also serves for process monitoring and controlling. Detailed monitoring information principally supports the subsequent process improvement phase. Based on long-term monitoring data, those process instances can be identified which have been most successful based on process mining methods (van der Aalst 2011), which can, furthermore, support reference modeling in particular areas. Moreover, valuable information on anomalies or critical points in inter-organizational process definitions can be put together and serve for the following optimization and improvement phase as well as for strategic decisions.

Besides the topics concerning the phases of the life cycle, there are superordinated concepts which are relevant for different phases. Process mining approaches and tools such as ProM (http:// www.processmining.org) can support process modeling and improvement, the monitoring of executed process instances as well as the development of new process strategies based on information extracted from log files (van der Aalst et al. 2007). Furthermore, the idea of large process repositories for the management and coordination of many different types of process models is of great relevance for subsequent life cycle phases, especially for similarity search (Kunze and Weske 2010) or cluster-based process model analysis (Niemann et al. 2010). Large repositories containing reference models offer interesting possibilities for best practice analysis and benchmarking initiatives. Regarding large process repository management, some innovative approaches and tools exist, e.g., APROMORE (http:// www.apromore.org) which offers advanced possibilities of large repository management for process models based on different modeling languages ( $\mathrm{La}$ Rosa et al. 2011). Another interesting concept concerning BPM-in-the-Large is the idea of BPM-as-a-Service as an innovative architecture approach for BPM systems (BPMS). This approach aims at providing flexibly composable BPM services, e.g., services for the transformation of models into different languages, 
for model evaluation, process mining, or process related telecommunication services organized in service-oriented architectures (SOA) (Houy et al. 2010c). BPM-as-a-Service offers the potential to run highly scalable BPMS in practice and is thus a promising architecture approach for future BPM initiatives.

\section{Significance for Business and Information Systems Engineering (BISE)}

Both BPM research and applications of BPM technology are characterized by design-orientation and focus on the interplay between organizations and information systems. This fits well with the general scope and focus of BISE. Furthermore, BPM methods, techniques and tools are meanwhile widely used and crucial for the success of many organizations. The practical relevance of these methods, techniques, and tools as well as the presented current challenges concerning the increasing complexity of real-life BPM makes BPM-in-the-Large a highly significant topic for future BISE research. Design-oriented research initiatives should address these current challenges and develop relevant approaches for handling complexity in BPM practice.

\section{Conclusion}

In this article, we have given pointers to current topics and research initiatives concerning BPM-in-the-Large as an umbrella term for the description of approaches for complexity handling in reallife BPM scenarios. In this context, BPMin-the-Large should not be understood as a new method or tool but as a research stream focusing on relevant challenges of current BPM practice. Promising approaches that assist in making BPM-inthe-Large a reality are currently developed and investigated by the BISE community.

\section{References}

Bandinelli S, Fuggetta A, Grigolli S (1993) Process modelling in-the-large with SLANG. In: Proceedings of the second international conference on the software process, Berlin, pp 75-83
Bertram M (1994) Data modelling in the large. ACM SIGMOD Record 23(4):8-12

Chiang JC (1987) Software engineering in the large. In: Proceedings of the national computer conference, Chicago, pp 475.

DeRemer F, Kron H (1975) Programmingin-the-large versus programming-in-thesmall. In: The international conference on reliable software, Los Angeles, pp 114-121

Dollmann T, Houy C, Fettke P, Loos P (2011) Collaborative business process modeling with CoMoMod - a toolkit for model integration in distributed cooperation environments. In: Reddy S, Tata S (eds) Proceedings of the 20th IEEE international conference on collaboration technologies and infrastructures. IEEE international workshops on enabling technologies: infrastruc ture for collaborative enterprises (WETICE2011), Paris, pp 217-222

Fettke P, Loos P (2004) Referenzmodellierungsforschung. WIRTSCHAFTSINFORMATIK 46(5):331-340

Gottschalk F, van der Aalst WMP, JansenVullers M, La Rosa M (2008) Configurable workflow models. International Journal on Cooperative Information Systems 17(2):177-221

Grabski B, Günther S, Herden S, Krüger L, Rautenstrauch C, Zwanziger A (2007) Very large business applications. Informatik Spektrum 30(4):259-263

Graw G, Gruhn V (1995) Process management in-the-many. In: Schäfer W (ed) Software process technology. Lecture notes in computer science, vol 913. Springer, Berlin, pp 163-178

Houy C, Fettke P, Loos P (2010a) Empirical research in business process management - analysis of an emerging field of research. Business Process Management Journal 16(4):619-661

Houy C, Fettke $\mathrm{P}$, Loos $\mathrm{P}$, van der Aalst WMP, Krogstie J (2010b) BPM-in-the-large towards a higher level of abstraction in business process management. In: Janssen M, Lamersdorf W, Pries-Heje J, Rosemann $M$ (eds) E-government and e-services (EGES)/Global information systems processes (GISP) 2010, Brisbane. Advances in information and communication technology (IFIP AICT), vol 334. Springer, Berlin, pp 237-248

Houy C, Reiter M, Fettke P, Loos P (2010c) Potentiale serviceorientierter Architekturen für Software-Werkzeuge des Geschäftsprozessmanagements. In: Esswein W, Turowski K, Juhrisch M (eds) Modellierung betrieblicher Informationssysteme (MobIS2010). Gesellschaft für Informatik, Bonn pp 211-227

Jørgensen H, Krogstie J (2008) Interactive models for virtual enterprises. In: Clark $S$ (ed) End user computing: concepts, methodologies, tools, and application. IGI Global, Hershey, pp 715-730

Krogstie J, Sindre G, Jørgensen H (2006) Process models representing knowledge for action: a revised quality framework. European Journal of Information Systems 15(1):91-102

Kunze M, Weske M (2010) Metric trees for efficient similarity search in large process model repositories. In: Su J, zur Muehlen M (eds) BPM 2010 workshops, Lecture notes in business information processing, vol 66 Springer, Berlin, pp 535-546
Kurz M (2011) BPM 2.0: Selbstorganisation im Geschäftsprozessmanagement. In: Sinz EJ, Bartmann D, Bodendorf F, Ferst OK (eds) Dienstorientierte IT-Systeme für hochflexible Geschäftsprozesse. Schriften aus der Fakultät Wirtschaftsinformatik und Angewandte Informatik der Otto-FriedrichUniversität Bamberg, vol 9. University of Bamberg Press, Bamberg, pp 193-216

La Rosa M, Reijers HA, van der Aalst WMP, Dijkman RM, Mendling J, Dumas $M$, García-Bañuelos L (2011) APROMORE: an advanced process model repository. Expert Systems with Applications 38(6): 7029-7040

Mendling J, Verbeek HMW, van Dongen BF, van der Aalst WMP, Neumann G (2008) Detection and prediction of errors in EPCs of the SAP reference model. Data \& Knowledge Engineering 64(1):312-329

Niemann M, Siebenhaar M, Eckert J, Steinmetz R (2010) Process model analysis using related cluster pairs. In: Su J, zur Muehlen M (eds) BPM 2010 workshops, Lecture notes in business information processing, vol 66 . Springer, Berlin, pp 547-558

Raduescu C, Tan HM, Jayaganesh M, Bandara W, zur Muehlen M, Lippe S (2006) A framework of issues in large process modeling projects. In: Ljungberg J, Andersson M (eds) Proceedings of the 14th European conference on information systems, Göteborg

Rittgen P (2009) Collaborative modeling of business processes: a comparative case study. In: Proceedings of the 2009 ACM symposium on applied computing, Honolulu, pp 225-230

Scheer A-W (1994) Wirtschaftsinformatik Referenzmodelle für industrielle Geschäftsprozesse. Springer, Berlin

Scheer A-W, Hars A (1992) Extending data modeling to cover the whole enterprise. Communications of the ACM 35(9):166172

van der Aalst WMP (2011) Process mining: discovery, conformance and enhancement of business processes. Springer, Berlin

van der Aalst WMP, Reijers HA, Weijters AJMM, van Dongen BF, Alves de Medeiros AK, Song M, Verbeek HMW (2007) Business process mining: an industrial application. Information Systems 32(5):713-732

van Looy A (2010) Does IT matter for business process maturity? A comparative study on business process maturity models. In: Meersman R, Herrero P (eds) OTM 2010 workshops. Lecture notes in computer science, vol 6428. Springer, Berlin, pp 687697

Vanderhaeghen D, Fettke P, Loos P (2010) Organisations- und Technologieoptionen des Geschäftsprozessmanagements aus der Perspektive des Web 2.0. Ergebnisse eines gestaltungsorientierten Forschungsansatzes unter besonderer Berücksichtigung von Selbstorganisation und kollektiver Intelligenz. WIRTSCHAFTSINFORMATIK 52(1):17-32

Wiederhold G, Wegner P, Ceri S (1992) Toward megaprogramming. Communications of the ACM 35(11):89-99 